\title{
AVALIAÇÃO EXPERIMENTAL DE VIGAS COM EMENDAS DE TOPO COLADAS COM COBREJUNTAS DE MADEIRA DE EUCALIPTO ${ }^{1}$
}

Moisés Silveira Lobão², Ricardo Marius Della Lucia ${ }^{3}$, Márcio Sampaio Sarmet Moreira ${ }^{4}$, Benedito Rocha Vital $^{3}$, Rita de Cássia Santana Alvarenga ${ }^{5}$ e Adriana de Fátima Gomes Gouvêa ${ }^{6}$

\begin{abstract}
RESUMO - Este trabalho teve como objetivos construir, testar e avaliar o comportamento de vigas de madeira de eucalipto com emendas de topo ligadas por cobrejuntas inteiramente colados com adesivo resorcinólico e compará-las com o comportamento de vigas maciças feitas do mesmo material. Para isso, obteve-se um lote de madeira de Eucalyptus grandis seca em estufa. Realizou-se a caracterização completa da madeira de acordo com a norma NBR7190/ 97. Protótipos menores das vigas foram construídos a partir de tábuas retiradas ao acaso com as dimensões de $10 \mathrm{~cm}$ de largura, $3 \mathrm{~cm}$ de espessura e $170 \mathrm{~cm}$ de comprimento nas testemunhas e $85 \mathrm{~cm}$ nas duas partes da alma das vigas a serem coladas com cobrejuntas compostas por tábuas de 35 e $43 \mathrm{~cm}$ de comprimento e 1,5 cm de espessura. Essas vigas com 160 cm de vão foram ensaiadas até a ruptura. Concluiu-se que a melhor configuração foi o cobrejunta que ocupava $25 \%$ da superfície lateral das tábuas. As vigas de tamanho real foram construídas com tábuas de $20 \mathrm{~cm}$ de largura, $6 \mathrm{~cm}$ de espessura e $420 \mathrm{~cm}$ de comprimento nas testemunhas e duas tábuas com $210 \mathrm{~cm}$ de comprimento e mesma espessura e largura nas vigas com emendas. Estas apresentaram excelente desempenho em termos de resistência, em alguns casos, superando a resistência da viga-testemunha. Quanto à rigidez, o desempenho foi considerado adequado, já que os deslocamentos das vigas com cobrejuntas foram em média 20\% inferiores aos da viga-testemunha submetida a uma mesma magnitude de carga, o que as proporciona melhor desempenho estrutural.
\end{abstract}

Palavra-chave: Vigas laminadas coladas, Eucalipto e Adesivo resorcinol formaldeído.

\section{EXPERIMENT EVALUATION OF GLUED BEAMS MADE WITH END-GRAIN JOINTS AND SIDE MEMBERS OF EUCALYPT WOOD}

\begin{abstract}
The objective of the present work was to construction, to test and to evaluate the behavior of wooden beams made of eucalyptus boards with mid-span end-grain joints. A resorcinol-formaldehyde glue was used as adhesive and the joints were covered by side members of the same species of wood. Strength and stiffness of these beams were compared with the results obtained for solid beams. Eucalyptus lumber was purchased for this purpose. Wood properties were determined for these two sub-samples, according to the recommendations of the Brazilian Association of Testing Standards, NBR 7190/97. Prototype beams were built to find the best size of the side members that symmetrically covered the joints. These beams had a length of $170 \mathrm{~cm}, 3 \mathrm{~cm}$ of width and $10 \mathrm{~cm}$ of deepness with cobrejuntas consist of boards 35 and, or $43 \mathrm{~cm}$ long and $1.5 \mathrm{~cm}$ thickness and were tested to failure using a center load on a $160-\mathrm{cm}$ span. It was found that a $1.5 \mathrm{~cm}$ thick side member should cover at least $25 \%$ of the two sides of the beam to give the same results of strength and stiffness of solid $170 \mathrm{~cm}$ long beams. Larger beams were then built and tested. They had a length of $420 \mathrm{~cm}, 20 \mathrm{~cm}$ of deepness and $6 \mathrm{~cm}$ of width the controls were built of a single piece of lumber; the others were made of 210 $\mathrm{cm}$ long boards, joined at mid-section by $100 \mathrm{~cm}$ long, $3 \mathrm{~cm}$ thick side members. After the test, these glued beams presented strength similar to the control witness, but the displacements of beams with cobrejuntas were on average $20 \%$ lower than the control, submitted showing a better structural performance.
\end{abstract}

Keywords: Glued laminated beams, Eucalyptus and Resorcinol-formaldehyde adhesive.

\footnotetext{
${ }^{1}$ Recebido em 15.10.2008 e aceito para publicação em 15.11.2011

${ }^{2}$ Centro de Ciências Biológicas e da Natureza, Universidade Federal do Acre, UFAC, Brasil. E-mail: <moises_lobao@yahoo.com.br>. ${ }^{3}$ Departamento de Engenharia Florestal, Universidade Federal de Viçosa, UFV, Brasil. E-mail: <rdlucia@ufv.br>e $<$ bvital@ufv.br>.

${ }^{4}$ Departamento de Engenharia Civil, Universidade Federal de Viçosa, UFV, Brasil. E-mail: <msarmet@ufv.br>.

${ }^{5}$ Departamento de Engenharia Civil, Universidade Federal de Viçosa, UFV, Brasil. E-mail: <ritadecassia@ufv.br>.

${ }^{6}$ Universidade do Estado de Mato Grosso, Campus de Cáceres, Programa de Pós-graduação em Ciências Ambientais. E-mail: <afgomes123@hotmail.com>.
} 


\section{INTRODUÇÃO}

A madeira apresenta propriedades mecânicas que permitem sua aplicação em estruturas da construção civil, inclusive naquelas de grandes vãos, principalmente devido à sua elevada resistência específica. Uma das dificuldades práticas dessas aplicações consiste na execução de ligações eficientes das peças componentes (MOLINA; CALIL JUNIOR, 2005).

As ligações coladas em áreas limitadas, dependendo da aplicação específica (geometria e ações aplicadas), podem ser solicitadas por diferentes esforços (normal, flexão e cisalhamento), e as superfícies coladas correspondentes também podem ser submetidas a complexos estados de tensões, podendo definir planos preferenciais de ruptura (LIMA JUNIOR; DIAS, 2001).

Quando se pensam em espécies de rápido crescimento como alternativa para produção de madeira, o gênero Eucalyptus se apresenta como opção potencial das mais importantes não somente por sua capacidade produtiva e adaptabilidade a diversos ambientes, mas, sobretudo, pela grande diversidade de espécies. E isso torna possível atender aos requisitos tecnológicos dos mais diversos segmentos da produção industrial madeireira (PONCE, 1995).

Poucas décadas de pesquisa começam a mudar a história do eucalipto no Brasil. De madeira de péssima qualidade e de vilão da natureza, acusado de extenuar os solos, consumir água em demasia, afugentar a fauna e impedir o consorciamento com outras culturas, o eucalipto vem-se transformando em alternativa de madeira de qualidade para aplicação na indústria de móveis, na marcenaria em geral e na construção civil, pois hoje cresce a preocupação ecológica de redução das pressões sobre as florestas nativas, principalmente da Amazônia (PEREIRA et al., 2000).

Apesar das incessantes pesquisas realizadas para melhorar a qualidade da madeira de eucalipto, ainda se está longe de atingir níveis adequados para obtenção de peças de grandes dimensões livres de defeitos. Assim, é necessário um estudo de alternativas que viabilizem o uso da madeira do eucalipto na confecção de peças estruturais para a construção civil (LOBÃO et al., 2004).

Segundo Panshin e De Zeeuw (1980), a resistência da madeira expressa sua capacidade de suportar cargas e forças, e essa propriedade está intimamente relacionada com a sua densidade. Nesse contexto, o principal objetivo deste trabalho foi avaliar o comportamento das vigas de madeira de eucalipto ligadas por cobrejuntas coladas à alma dessas peças com adesivo resorcinol-formaldeído e compará-las com o comportamento de vigas maciças do mesmo material. Experimentos auxiliares foram feitos com objetivos específicos para a consecução do trabalho, os quais compreenderam a caracterização do lote da madeira, a adesão desta em diferentes planos e a confecção, solidarização e caracterização das propriedades dos protótipos e das vigas em tamanho real.

\section{MATERIAL E MÉTODOS}

O trabalho foi desenvolvido no Laboratório de Propriedades Físicas e Mecânicas da Madeira do Departamento de Engenharia Florestal da Universidade Federa de Viçosa (UFV), que dispunha de equipamentos para caracterização do lote da madeira e realização de ensaios de flexão das vigas com emendas e cobrejuntas coladas.

\subsection{Caracterização das propriedades físico-mecânicas da madeira}

A madeira de Eucalyptus grandis foi adquirida no mercado local, seca em estufa e aclimatizada em Viçosa, MG. A densidade aparente foi determinada seguindo os procedimentos de Vital (1984), pelo método de imersão em água e determinação do volume ( $\mathrm{U}=12 \%$ ) da amostra pelo empuxo do líquido, registrado em balança.

A caracterização completa das propriedades de resistência da madeira para projeto de estruturas foi feita de acordo com o método de ensaio especificado na NBR 7190 (ABNT, 1997), que exige a determinação dos valores de resistência da ruptura à compressão paralela e perpendicular às fibras, tração paralela às fibras, flexão estática e cisalhamento longitudinal às fibras, a serem referidos à condição-padrão de umidade (U $=12 \%)$ :

A rigidez da madeira foi medida pelo valor médio do módulo de elasticidade determinado na fase de comportamento elástico-linear. Para isso, respeitaramse os métodos de ensaio especificados na NBR 7190, da ABNT (1997).

\subsection{Adesão da madeira em diferentes planos}

Anteriormente à colagem das vigas, foram realizados ensaios com o intuito de verificar a qualidade da adesão 
da madeira com o adesivo resorcinol-formaldeído. Nesses testes de colagem foram utilizados corpos-de-prova que constituíam seis tratamentos, em que se variaram a densidade e direção das fibras das madeiras que formavam as duas tábuas das juntas, com todos os testes recebendo adesivo na proporção de $300 \mathrm{~g} / \mathrm{m}^{2}$ e sendo submetidos a uma pressão aproximada de 1 MPa, durante $8 \mathrm{~h}$.

A Figura 1 ilustra o formato e disposição das fibras nos corpos-de-prova produzidos e ensaiados.

O teste foi conduzido segundo as variáveis que compreenderam, respectivamente, a resistência ao cisalhamento na madeira sólida ou na linha de cola da madeira colada, fibras paralelas ou perpendiculares entre si e se o corpo-de-prova era composto por madeira leve, pesada ou leve com pesada. Foram preparados, no mínimo, 12 corpos-de-prova de cada tratamento, totalizando 124 corpos-de-prova ensaiados (Tabela 1 ). Determinaram-se a densidade e teor de umidade de cada uma das duas partes dos corpos-de-prova, depois de levados à ruptura para determinação da resistência.

Após a determinação da densidade e do teor de umidade, as partes pertencentes ao mesmo corpo-deprova foram reunidas para avaliação do percentual de falha na madeira. Utilizou-se uma série de lâminas transparentes, previamente quadriculadas, e com dimensões que atendessem à variabilidade observada para as dimensões dos corpos-de-prova. O desempenho da propriedade de resistência na linha de cola dos tratamentos foi avaliado por meio da análise de variância da resistência média apresentada. Já o percentual de falha na madeira foi avaliado apenas através da média de falha apresentada.

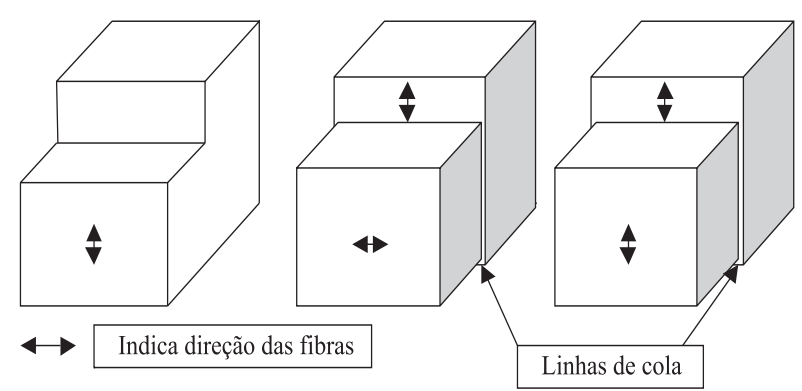

Figura 1 - Geometria e orientação das fibras nos corpos-deprova de cisalhamento da madeira sólida e da colada.

Figure 1-Geometry and fiber orientation of the shear specimens.
Tabela 1 - Tipos de tratamentos dos testes de adesão da madeira em diferentes planos.

Table 1 - Treatment types for the shear specimens.

\begin{tabular}{llc}
\hline $\begin{array}{l}\text { Resistência ao } \\
\text { cisalhamento }\end{array}$ & \multicolumn{1}{c}{$\begin{array}{c}\text { Orientação das } \\
\text { fibras eDensidade }\end{array}$} & $\begin{array}{r}\text { Número de } \\
\text { repetições }\end{array}$ \\
\hline $\begin{array}{l}\text { Na madeira } \\
\text { sólida }\end{array}$ & $\begin{array}{l}\text { Paralela madeira leve } \\
\text { Paralela madeira pesada }\end{array}$ & 12 \\
\hline \multirow{4}{*}{ Na linha } & Paralela madeira leve & 12 \\
de cola & Paralela madeira pesada & 15 \\
& Paralela madeira leve com pesada & 13 \\
& Perpendicular madeira leve & 21 \\
& Perpendicular madeira pesada & 18 \\
\hline
\end{tabular}

\subsection{Confecção e caracterização das propriedades mecânicas das vigas}

As tábuas foram desempenadas e cortadas com cerca de $10 \mathrm{~cm}$ de largura, $3 \mathrm{~cm}$ de espessura e $170 \mathrm{~cm}$ de comprimento para confecção das vigas-testemunha e $85 \mathrm{~cm}$ para as duas lâminas da alma das vigas com cobrejuntas. Para a feitura dos cobrejuntas, utilizaram-se peças de 35 e $43 \mathrm{~cm}$ de comprimento e $1,5 \mathrm{~cm}$ de espessura, que serviram para reforçar a colagem da emenda das lâminas da alma das vigas com cobrejuntas. Essas diferentes configurações de vigas com 160 cm de vão foram ensaiadas até a ruptura. Realizados esses ensaios preliminares nos protótipos, as melhores configurações quanto às características de resistência foram utilizadas para a confecção de vigas em escala real.

Todas as vigas de $400 \mathrm{~cm}$ de vão (tamanho real) tiveram aproximadamente as seguintes dimensões: lâminas de $20 \mathrm{~cm}$ de largura, $6 \mathrm{~cm}$ de espessura e $420 \mathrm{~cm}$ de comprimento para a alma da testemunha e com $210 \mathrm{~cm}$ de comprimento para as vigas com cobrejuntas. Estas últimas foram feitas com $1 \mathrm{~m}$ de comprimento e com a mesma largura da alma e espessura de aproximadamente $3 \mathrm{~cm}$, para reforçar as emendas entre as lâminas de $210 \mathrm{~cm}$ de comprimento, conforme mostrado na Figura 2.

O adesivo resorcinólico-formaldeído se apresentava em dois componentes (a resina e o endurecedor), que foram misturados nas proporções de 5/1 (5 partes de resina para 1 de catalisador) até se conseguir uma solução homogênea, sem vestígio de material não disperso. Na sequência, aplicou-se o adesivo com pincel nas superfícies das pranchas de madeira a serem coladas. Logo após, essas peças foram unidas umas às outras e encaminhadas à prensa, onde ficaram sob uma pressão

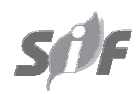

Revista Árvore, Viçosa-MG, v.36, n.2, p.357-364, 2012 


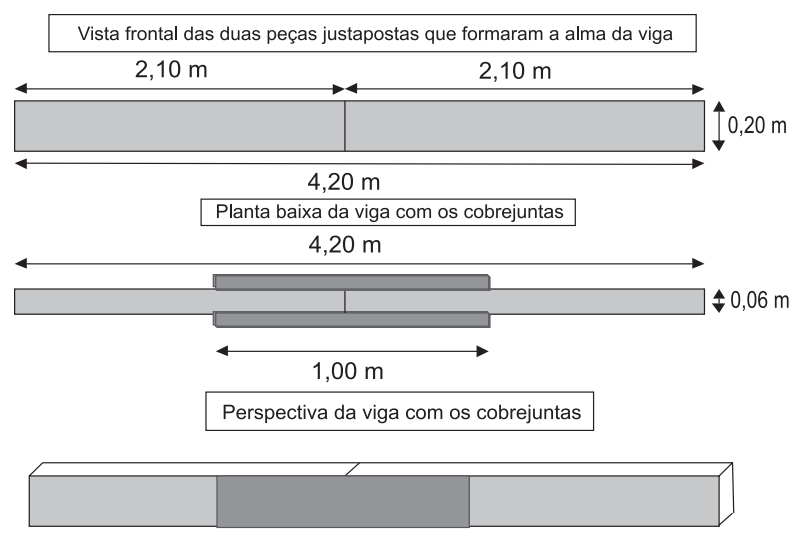

Figura 2 - Geometria, dimensões e os detalhes das vigas com emendas e cobrejuntas.

Figure 2-Geometry, sizes and the details of the beams with joints and side members.

de $1 \mathrm{MPa}$ até a cura do adesivo (aproximadamente $8 \mathrm{~h}$ ). A peça assim fabricada não foi submetida a nenhum tipo de esforço até que se completassem pelo menos oito dias após a colagem (LUCIA e VITAL, 1981).

Seguiu-se a Norma NBR 7190, da ABNT (1997), para determinação das propriedades mecânicas de vigas coladas avaliadas por flexão simples, como se fossem peças maciças de seção retangular. Os ensaios de flexão nos modelos, tanto em escala reduzida quanto no de tamanho real, foram conduzidos no quadro de reação, localizado nas dependências do Laboratório de Propriedades Físicas e Mecânicas da Madeira - Campus da UFV (PETRAUSKY, 1998).

No quadro de reação, as cargas foram aplicadas por intermédio de um cilindro hidráulico e lidas por intermédio de duas células de carga, localizadas nos apoios. Durante os ensaios, procurou-se acompanhar os deslocamentos de flexão das peças sob carga crescente, utilizando relógios comparadores (precisão de 0,01 mm) para obtenção do módulo de rigidez das vigas. Em todos os casos, uma carga concentrada foi aplicada no ponto central do vão da viga, ou seja, no ponto da viga onde as distâncias da aplicação da carga em relação aos apoios se igualavam. O sistema utilizado para realização dos testes encontra-se esquematizado na Figura 3.

Foi determinada, em cada ensaio, a carga de ruptura das vigas, além de terem sido tomadas medidas de deformação para cálculo da rigidez das peças. Os resultados foram analisados para determinar as diferenças entre a viga maciça e as vigas com cobrejuntas colados.

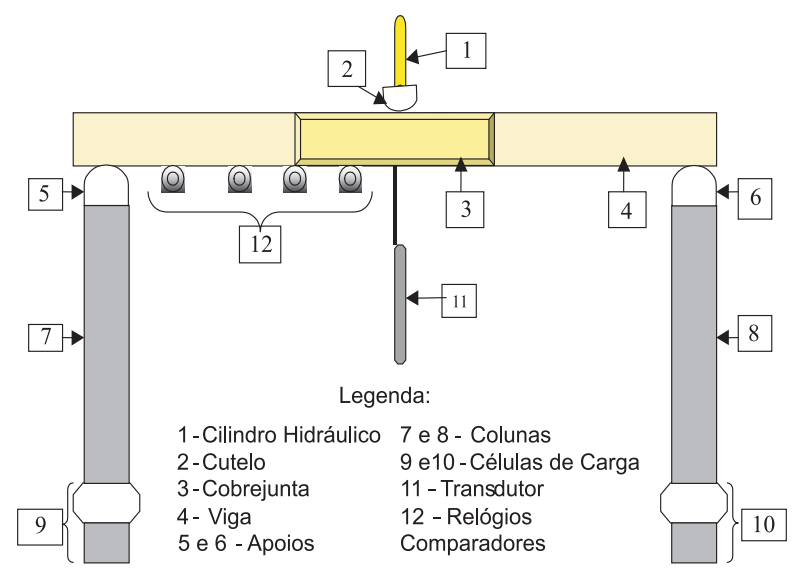

Figura 3 - Quadro de reação e aparelhagem utilizada para ensaios à flexão das vigas com emendas e cobrejuntas.

Figure 3-Reaction frame and equipment used during bending tests of the beams.

\section{RESULTADOS E DISCUSSÃO}

\subsection{Determinação das propriedades físico-mecânicas da madeira}

Os resultados médios e os coeficientes de variação das propriedades físicas e mecânicas da madeira de Eucalyptus grandis estão apresentados na Tabela 2.

\subsection{Teste de adesão da madeira em diferentes planos}

Na Tabela 3 estão especificados os tipos de tratamentos a que foram submetidos os corpos-de-prova de cisalhamento, com os respectivos valores de resistência média à ruptura e os valores corrigidos para o teor de umidade de $12 \%$, bem como a densidade média do lote e a média do percentual de falha na madeira, com os respectivos desvios-padrão. Para efeito de comparação, incluiu-se no quadro a resistência ao cisalhamento da madeira "sólida".

Vê-se que os resultados de resistência à ruptura, por cisalhamento das juntas coladas, variaram de acordo com cada tratamento. Utilizando o teste de médias (T-studentes) para amostras independentes, observou-se diferença sempre significativa $(\mathrm{p}<0,05)$ entre os valores médios dos tratamentos em que foram coladas tábuas com as fibras nos sentidos perpendicular e paralelo ao esforço (Tabela 3). Tábuas coladas com as fibras paralelas ao esforço não mostraram diferença significativa entre seus valores médios de resistência 
Tabela 2 - Valores médios experimentais (com desvio-padrão entre parênteses), valores corrigidos para o teor de umidade de $12 \%$ e valores característicos experimentais das propriedades físico-mecânicas da madeira de eucalipto.

Table 2 - Mean experiment values (with standard deviation) corrected to $12 \%$ moisture content and characteristic values of the physical and mechanical properties of eucalypt timber.

\begin{tabular}{|c|c|c|c|}
\hline Propriedades físicas & \multicolumn{2}{|c|}{ Valor médio } & Desvio-padrão \\
\hline "Densidade aparente" (massa e volume a 12\% de umidade) & \multicolumn{2}{|c|}{$721 \mathrm{~kg} / \mathrm{m}^{3}$} & $167,74 \mathrm{~kg} / \mathrm{m}^{3}$ \\
\hline Teor de umidade & \multicolumn{2}{|c|}{$12,475 \%$} & $1,75 \%$ \\
\hline Propriedades mecânicas & $\begin{array}{l}\text { Valor médio } \\
\text { (MPa) }\end{array}$ & $\begin{array}{l}\text { Valor médio corrigido } \\
\text { (MPa) } \mathrm{U}=12 \%\end{array}$ & $\begin{array}{l}\text { Valor característico } \\
\mathrm{MPa} \text { ) }\end{array}$ \\
\hline $\begin{array}{r}\text { Compressão paralela às fibras }\left(f_{\mathrm{C} 0}\right) \\
\text { Desvio-padrão }\end{array}$ & $\begin{array}{c}55,9 \\
(5,47)\end{array}$ & 55,5 & 54,2 \\
\hline Compressão perpendicular às fibras ( $\left.\mathrm{f}_{\mathrm{C} 90}\right)$ & $4,9(1,59)$ & 4,9 & 4,4 \\
\hline Cisalhamento $\left(f_{v}\right)$ & $10,2(0,65)$ & 10,2 & 9,2 \\
\hline Tração paralela às fibras $\left(\mathrm{f}_{\mathrm{t} 0}\right)$ & $84,5(28)$ & $84,5(23,85)$ & 65,35 \\
\hline Flexão $\left(f_{b}\right)$ & $76,35(16,18)$ & $78,0(15,65)$ & 65,4 \\
\hline Módulo de elasticidade à compressão paralela às fibras $\left(\mathrm{E}_{\mathrm{c} 0}\right)$ & $19.137(3863)$ & $18.947(3863)$ & 13.390 \\
\hline Módulo de elasticidade à compressão perpendicular às fibras $\left(\mathrm{E}_{\mathrm{c} 90}\right)$ & $564(223)$ & $565(229)$ & 474 \\
\hline Módulo de elasticidade à tração paralela às fibras $\left(\mathrm{Ef}_{\mathrm{t} 0}\right)$ & $16.990(3512)$ & $18.793(3956)$ & 13.321 \\
\hline Módulo de elasticidade à flexão $\left(\mathrm{E}_{\mathrm{F}}\right)$ & $15.275(2436)$ & $15.596(2.019)$ & 13.690 \\
\hline
\end{tabular}

Tabela 3 - Valores médios da resistência ao cisalhamento das juntas coladas e da porcentagem de falha na madeira, com os respectivos desvios-padrão (entre parênteses).

Table 3 - Mean values of shear strength of the glued joints and percentage of wood failure with the respective standard deviation.

\begin{tabular}{|c|c|c|c|c|c|}
\hline & \multirow[b]{2}{*}{ Situação } & \multicolumn{4}{|c|}{ Resistência ao cisalhamento } \\
\hline & & $\begin{array}{l}\text { Valor médio } \\
(\mathrm{MPa})\end{array}$ & $\begin{array}{c}\text { Valor corrigido para } \\
\mathrm{U}=12 \%(\mathrm{MPa})\end{array}$ & $\begin{array}{c}\text { Densidade média da } \\
\text { madeira no ensaio }\left(\mathrm{kg} / \mathrm{m}^{3}\right)\end{array}$ & $\begin{array}{l}\text { Média da falha na } \\
\text { madeira (\%) }\end{array}$ \\
\hline \multirow{2}{*}{ Madeira "sólida" } & Baixa densidade & $8,3(0,96)$ & 8,7 & 533 & - \\
\hline & Alta densidade & $12,1(1,45)$ & 12,2 & 809 & - \\
\hline \multirow{6}{*}{ Junta colada } & $\begin{array}{l}\text { Fibras paralelas } \\
\text { Baixa densidade }\end{array}$ & $7,7(2,18)$ & 7,9 & 582 & 84 \\
\hline & $\begin{array}{l}\text { Fibras paralelas } \\
\text { Alta densidade }\end{array}$ & $9,6(2,33)$ & 9,7 & 823 & 82 \\
\hline & $\begin{array}{l}\text { Fibras paralelas } \\
\text { Baixa com alta densidade }\end{array}$ & $5,2(2,80)$ & 5,6 & 532 & 69 \\
\hline & $\begin{array}{l}\text { Fibras perpendiculares } \\
\text { Baixa densidade }\end{array}$ & $3,2(1,05)$ & 3,3 & 626 & 75 \\
\hline & $\begin{array}{l}\text { Fibras perpendiculares } \\
\text { Alta densidade }\end{array}$ & $7,7(1,82)$ & 8,0 & 759 & 71 \\
\hline & $\begin{array}{l}\text { Fibras perpendiculares } \\
\text { Baixa com alta densidade }\end{array}$ & $3,1(0,70)$ & 3,2 & 554 & 75 \\
\hline
\end{tabular}

e a média da madeira sólida. A colagem de tábuas de densidades muito diferentes produziu juntas com resistência menor que a da madeira menos densa e, portanto, não favoreceu o incremento da resistência desses corpos-de-prova, em que a ruptura se deu sempre na madeira menos densa, como observado após os ensaios. A porcentagem de falha na madeira foi, em todos os casos, superior a $69 \%$, indicando facilidade de adesão da madeira utilizada e corroborando as conclusões anteriores, isto é, de que as diferenças 
verificadas devem ser, de fato, atribuídas às diferenças de densidade ou de orientação das fibras e não à técnica de adesão.

Os resultados dos testes de cisalhamento na linha de cola serviram para subsidiar a confecção dos cobrejuntas, principalmente no que se refere à resistência ao cisalhamento na linha de cola. Analisando os resultados, viu-se (Tabela 3) que o valor mais elevado de resistência foi o do tratamento do corpo colado com madeiras de alta densidade e com as fibras paralelas entre si, atingindo resistência média corrigida para a umidade de $12 \%$, de 9,7 MPa, seguido dos tratamentos com madeiras de alta densidade coladas com as fibras perpendiculares entre si, que atingiram resistência média corrigida de 8,0 MPa e com madeiras de baixa densidade coladas com as fibras paralelas entre si, que atingiram média de 7,9 MPa. Outro dado importante foi que o tratamento do corpo colado com madeiras de baixa densidade com fibras perpendiculares entre si e o constituído por madeira de alta e baixa densidades, com fibras também perpendiculares, atingiram praticamente a mesma resistência média de 3,2 e 3,3 $\mathrm{MPa}$, respectivamente. Após a análise desses dados, concluiu-se que a melhor opção para se empregarem os cobrejuntas seria solidarizando-os na viga com as fibras paralelas às da alma.

\subsection{Caracterização das propriedades mecânicas das vigas}

Foram confeccionadas, inicialmente, três vigas com 1,60 m de vão e com cobrejuntas de $35 \mathrm{~cm}$ de comprimento, $10 \mathrm{~cm}$ de largura e 1,5 cm de espessura, correspondendo a cerca de $20 \%$ da área total das faces da viga. Posteriormente, seis outras vigas foram confeccionadas também com 1,60 m de vão, mas com cobrejuntas de $43 \mathrm{~cm}$ de comprimento e largura de espessura igual à da viga anterior, atingindo cerca de $25 \%$ da área da face lateral da viga. A Tabela 4 descreve as cargas atingidas quando da ruptura das vigas.

Vê-se, na Tabela 4, que houve certa variabilidade nas “resistências” das vigas, o que já se poderia esperar por ser a madeira material tão heterogêneo. As vigas com cobrejuntas de $35 \mathrm{~cm}$ de comprimento atingiram "resistência” média de 60,87 MPa; aquelas com cobrejuntas de $43 \mathrm{~cm}$ de comprimento atingiram “resistência” média de 66,45 MPa, enquanto a média das vigas-testemunha foi de 60,43 MPa. Portanto, analisando as médias das "resistências", viu-se que
Tabela 4 - Carga de ruptura e resistência das vigas de 1,6 m de vão ensaiadas.

Table 4-Load at rupture, strength and stiffness of the 1.6meter beams.

\begin{tabular}{cccc}
\hline Vigas & $\begin{array}{c}\text { Carga de ruptura } \\
(\mathrm{N})\end{array}$ & $\begin{array}{c}\text { "Resistência” } \\
(\mathrm{MPa})\end{array}$ & $\begin{array}{c}\text { "E” } \\
(\mathrm{MPa})\end{array}$ \\
\hline Testemunhas No 1 & 9.030 & 71,6 & 10.172 \\
$\mathrm{~N}^{0}$ 2 & 5.550 & 44,5 & 8.985 \\
$\mathrm{~N}^{0}$ 3 & 7.740 & 65,2 & 11.220 \\
\hline Valores médios & 7.440 & 60,43 & 10.125 \\
\hline Com cobrejuntas & & & \\
de 35 cm & & & \\
VIGA 1 & 7.800 & 64,5 & 13.747 \\
VIGA 2 & 6.510 & 53,6 & 14.185 \\
VIGA 3 & 7.830 & 64,5 & 13.889 \\
\hline Valores médios & 7.380 & 60,87 & 13.940 \\
\hline Com cobrejuntas & & & \\
de 43 cm & & & \\
VIGA 1 & 5.630 & 45,2 & 9.759 \\
VIGA 2 & 6.270 & 50,7 & 11.090 \\
VIGA 3 & 11.360 & 92,3 & 11.271 \\
VIGA 4 & 10.420 & 84,7 & 10.842 \\
VIGA 5 & 7.010 & 56,1 & 13.412 \\
VIGA 6 & 8.300 & 69,7 & 14.398 \\
\hline Valores médios & 8.165 & 66,45 & 11.795 \\
\hline
\end{tabular}

as vigas com emendas com cobrejuntas se mostraram tão eficientes quanto as testemunhas. As de $25 \%$ de recobrimento mostraram, de fato, resistência média até superior, cerca de 9,96\% maior, que a média de resistência das testemunhas e das vigas com cobrejunta de $35 \mathrm{~cm}$ de comprimento.

A observação da resistência à ruptura das vigas com cobrejuntas serviu para subsidiar na decisão da escolha do protótipo a ser confeccionado em tamanho real. Viu-se que o cobrejunta deveria ter pelo menos $25 \%$ do comprimento da viga. Essa informação poderá subsidiar outros tipos de projetos estruturais, como na construção de uma ponte de madeira, cujo tabuleiro consista de tábuas colocadas lateralmente. Se as tábuas sofrem interrupções, uma destas deve estar distante pelo menos $25 \%$ do comprimento uma da outra.

Como se pode verificar a seguir, por ocasião da descrição das falhas ocorridas, esse incremento evitou, também, que o rompimento se iniciasse por cisalhamento entre o cobrejunta e a alma, mas, sim, que se desse por tração e compressão da alma, o que demonstrou a eficiência do cobrejunta como membro de ligação também em elementos fletidos. 
A análise de variância mostrou que o F não atingiu a significância, porém, pelos valores médios, notou-se que havia diferenças entre as médias, sendo o tratamento 3 , em que se usaram as vigas com cobrejuntas de $43 \mathrm{~cm}$ de comprimento, o que atingiu maior valor de resistência $(66,45)$, sendo, por isso, o protótipo escolhido para confecção das vigas de tamanho real.

Vê-se que as vigas com cobrejuntas têm carga de ruptura um pouco superior (mais 3,29\%) ou um pouco inferior $(10 \%)$, quando comparadas com a viga-testemunha, sem emendas. Assim, é possível que os cobrejuntas que ocupam $25 \%$ da área central possam ser utilizados na confecção de vigas que substituirão as vigas sólidas.

A viga de dimensão real, ou seja, de $400 \mathrm{~cm}$ de vão e cobrejuntas de $100 \mathrm{~cm}$ de comprimento, foi testada utilizando-se o mesmo sistema anterior. A Tabela 5 descreve os valores de resistência à flexão das vigas de tamanho real ensaiadas e as cargas atingidas por ocasião da ruptura.

A Tabela 5 também mostra os valores dos módulos de elasticidade (E) das vigas de $4 \mathrm{~m}$ ensaiadas.

Notou-se que as deformações em torno das diferentes distâncias das vigas-testemunha e com cobrejuntas possuem correlações bastante altas, o que demonstra que as vigas com cobrejuntas, quando submetidas a esforços de flexão, têm comportamentos muito parecidos com as vigas sólidas sem emendas, mostrando a mesma eficiência com o uso de madeiras de bitolas menores, o que pode favorecer o vencimento de grandes vãos. Karlsen et al. (19767 apud FERREIRA, 1999), utilizando uma estrutura do tipo caixão, com almas em madeira compensada e mesas em madeira maciça e com a utilização de lamelas de seção transversal, conseguiu considerável redução do peso próprio da estrutura lamelar, o que possibilitou vencer vãos com mais de $80 \mathrm{~m}$.

Além dessa vantagem, neste estudo pôde-se observar menor deformação (deslocamento) da viga com cobrejuntas em relação à viga-testemunha. Santana (1997), a partir de análise teórica do efeito da composição parcial de vigas compostas, observou que a influência dessa composição nos deslocamentos da viga pode reduzir tal efeito em até $20 \%$ em relação à viga simples de madeira, sendo os parâmetros influentes, além da
Tabela 5 - Cargas de ruptura e resistências à flexão das vigas de $4 \mathrm{~m}$ de vão ensaiadas.

Table 5 - Load at rupture, strength and stiffness of the 4meter beams.

\begin{tabular}{lccc}
\hline Viga & $\begin{array}{c}\text { Carga de } \\
\text { ruptura }(\mathrm{N})\end{array}$ & $\begin{array}{c}\text { “Resistência” } \\
(\mathrm{MPa})\end{array}$ & $\begin{array}{c}\text { “E” } \\
(\mathrm{MPa})\end{array}$ \\
\hline Testemunha & 27.950 & 65,80 & 10.831 \\
VIGA 1 & 28.870 & 66,99 & 14.387 \\
VIGA 2 & 25.410 & 60,06 & 13.124 \\
VIGA 3 & 25.180 & 62,05 & 12.897 \\
\hline Valores médios $^{1}$ & 26.487 & 63.03 & 13.469 \\
\hline
\end{tabular}

${ }^{1}$ Valores médios das vigas com cobrejuntas.

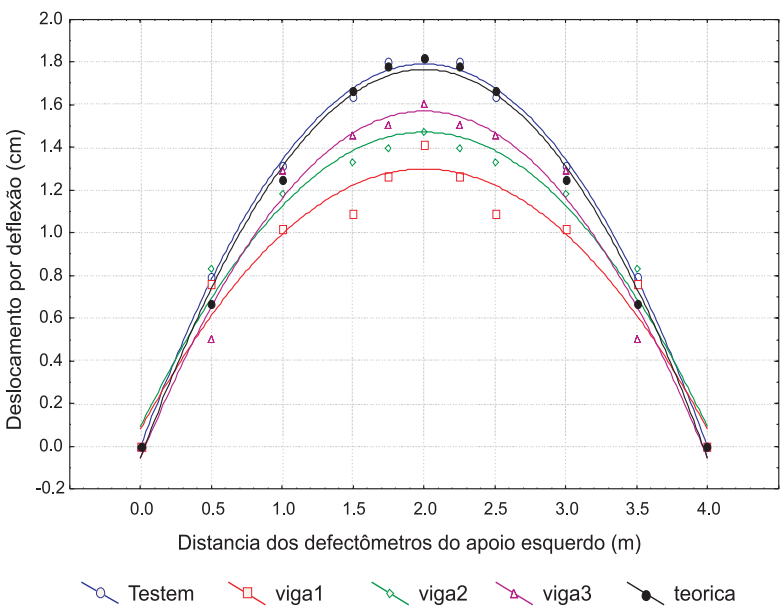

Figura 4 - Deslocamentos por deflexão em diferentes pontos ao longo do vão das vigas quando submetidas a uma carga de $6740 \mathrm{~N}$.

Figure 4-Deflection at different positions along the span of the beams due to a $6.740 \mathrm{~N}$ concentrated load.

rigidez da ligação, a área da mesa e o seu distanciamento do eixo da seção e do comprimento do vão.

\section{CONCLUSÕES}

- Os testes de adesão mostraram que a melhor configuração das vigas com cobrejuntas é aquela de madeiras coladas no sentido paralelo às fibras.

- Quanto aos protótipos das vigas, concluiu-se que a melhor configuração foi o de cobrejunta que ocupava pelo menos $25 \%$ da superfície lateral das tábuas; o protótipo tinha cobrejunta de $43 \mathrm{~cm}$ de comprimento.

${ }^{7}$ KARLSEN, G.G. et al. (1976). Wooden structures. Moscow, Mir Publ. Parte VIII, Cap.2, p.372-393: Segmental-lattice vaults. 
- As vigas de tamanho real apresentaram excelente desempenho em termos de resistência, em alguns casos superando as resistências da viga-testemunha.

- Quanto à rigidez, o desempenho foi considerado adequado, já que os deslocamentos das vigas com cobrejuntas foram bastante inferiores aos da viga-testemunha, submetida a uma mesma magnitude de carga, o que proporciona grande vantagem estrutural.

\section{REFERÊNCIAS}

ASSOCIAÇÃO BRASILEIRA DE NORMAS TÉCNICAS - ABNT. Projetos de estruturas de madeira - NBR 7190. Rio de Janeiro: 1997. 107p.

FERREIRA, N. S. S. Estruturas lamelares de madeira para coberturas. 1999. $250 \mathrm{f}$. Dissertação (Mestrado em Engenharia de Estruturas) - Escola de Engenharia de São Carlos/ Universidade de São Paulo, 1999.

LIMA JUNIOR, H. C.; DIAS, A. A. Vigas mistas de madeira de reflorestamento e bambu laminado colado: análise teórica e experimental. Revista Brasileira de Engenharia Agrícola e Ambiental, v.5, n.3, p.519-524, 2001.

LOBÃO, M. S. et al. Caracterização das propriedades fisico-mecânicas da madeira de eucalipto com diferentes densidades. Revista Árvore, v.28, n.6, p.889-894, 2004.

LUCIA, R. M. D.; VITAL, B. R.; Avaliação da qualidade de juntas coladas de madeira de 3 espécies de Eucalyptus. Revista Árvore, v.5, n.2, p.172-180, 1981.
MOLINA, J. C.; CALIL JUNIOR, C. Estudo da ancoragem de barras de aço coladas em peças estruturais de madeira. Revista Madeira Arquitetura e Engenharia, n. 16, maioagosto, 2005.

PANSHIN, A. J.; DE ZEEUW, C. Textbook of wood technology. 4.ed. New York: Mc-GrawHill, 1980.

PEREIRA, J. C. D. et al. Características da madeira de algumas espécies de eucalipto plantadas no Brasil. Colombo: Embrapa Florestas, 2000. 113p. (Embrapa Florestas. Documentos, 38).

PETRAUSKY, A.; DELLA LUCIA, R. M. Quadro de reação para ensaio de estruturas de madeira. In: ENCONTRO BRASILEIRO EM MADEIRAS E EM ESTRUTURAS DE MADEIRA, 6., 1998, Florianópolis. Anais... Florianópolis: Departamento de Engenharia Civil/UFSC, 1998. p.57-64.

PONCE, R. H. Madeira serrada de eucalipto: desafios e perspectivas. In: SEMINÁRIO INTERNACIONAL DE UTILIZAÇÃO DA MADEIRA DE EUCALIPTO PARA SERRARIA, São Paulo: 1995. Anais... São Paulo: 1995. p.50-58.

SANTANA, C. L. O. Vigas de madeira de seção composta com alma em chapa de compensado. 1997. 201f. Dissertação (Mestrado em...) - Faculdade de Engenharia Civil/ Universidade Estadual de Campinas, 1997.

VITAL, B. R. Métodos de determinação da densidade da madeira. Viçosa, MG: Universidade Federal de Viçosa, 1984. 15p. (Boletim Técnico, 1). 